\title{
High-performance polypyrrole functionalized PtPd electrocatalysts based on PtPd/PPy/PtPd three-layered nanotube arrays for the electrooxidation of small organic molecules
}

\begin{abstract}
Han $\mathrm{Xu}^{1,2}$, Liang-Xin Ding ${ }^{1,2}$, Chao-Lun Liang ${ }^{1}$, Ye-Xiang Tong ${ }^{1}$ and Gao-Ren $\mathrm{Li}^{1}$
Here, we report novel high-performance polypyrrole (PPy) functionalized PtPd electrocatalysts based on PtPd/PPy/PtPd threelayered nanotube arrays (TNTAs) for the electrooxidation of small organic molecules, such as methanol, ethanol and formic acid, which are superior fuels for direct alcohol fuel cells (DAFCs) or direct formic acid fuel cells (DFAFCs). The unique hollow structures, array structures and sandwich-like structures of PtPd/PPy/PtPd TNTAs will provide fast transport and short diffusion paths for electroactive species as well as a large exposed surface area for efficient interaction with electroactive species. In particular, the unique sandwich-like structure of PtPd/PPy/PtPd TNTAs results in electron delocalization among the Pt $4 f$ orbitals, Pd $3 d$ orbitals and PPy $\pi$-conjugated ligands, and in electron transfer from the PPy to Pt and Pd atoms, leading to higher contents of metallic Pt and Pd and synergistic effects for electrocatalytic reactions. Because of the above merits, the designed PtPd/PPy/PtPd TNTAs exhibit significantly improved catalytic activity and durability for the electrooxidation of small organic molecules compared with those of PtPd TNTAs and commercial Pt/C and Pd/C catalysts.
\end{abstract}

NPG Asia Materials (2013) 5, e69; doi:10.1038/am.2013.54; published online 8 November 2013

Keywords: electrocatalyst; electrodeposition; hybrid Pd/PPy/PtPd; nanotube array

\section{INTRODUCTION}

Platinum is the best electrocatalyst for fuel cells, which have been regarded as promising future power sources, although great progress has been made towards the fabrication of non-platinum electrocatalysts, such as the functionalized carbon-nanotubes/graphene and nonprecious metal oxides. ${ }^{1-5}$ However, several critical issues must be solved before Pt-based electrocatalysts can be commercialized. For example, the electrocatalytic reaction is kinetically limited, the low $\mathrm{CO}$ poisoning tolerance causes severe durability of catalyst, and the scale of Pt catalysts leads to high cost. ${ }^{6-10}$

To address these issues, many recent efforts have been devoted to synthesizing Pt-M bimetallic electrocatalysts (where $\mathrm{M}=\mathrm{Pd}, \mathrm{Co}, \mathrm{Ni}$, $\mathrm{Fe}, \mathrm{Au}, \mathrm{Cu}$, and so on). ${ }^{1-16}$ The bimetallic Pt-based electrocatalysts have unusual electronic structures and arrangements of surface atoms in the near-surface region, and accordingly exhibit improved electrocatalytic activity and cycle stability compared with the monometallic Pt. ${ }^{17-21}$ Because of the outstanding activity derived from the presence of powerful catalytic components of $\mathrm{Pt}$ and $\mathrm{Pd}$, the bimetallic PtPd composites are particularly favorable for reducing the
Pt consumption. ${ }^{22-30}$ An alternative approach is to tailor the nanostructures of Pt-based catalysts to obtain high performance. ${ }^{31-}$ 39 Noble metal nanomaterials embedded in one-dimensional (1D) nanotube arrays have been highlighted in literature reports. ${ }^{40-41}$ In contrast to nanoparticles, $1 \mathrm{D}$ nanotube arrays can obviously improve the mass transport and catalyst utilization because of their unique anisotropy and hollow nanostructures, which make them less vulnerable to dissolution, Ostwald ripening and aggregation during fuel cell operation. ${ }^{42-44}$ In addition, the hybridization method provides an effective strategy to enhance the performance of catalysts. ${ }^{45-51}$ Conducting polymers, such as polypyrrole (PPy) and polyaniline (PANI), have received special attention as dopants in catalyst applications because of their unique $\pi$-conjugated structures, which lead to good environmental stability, high electrical and proton conductivity in acidic environments and unique redox properties. ${ }^{52-56}$ Recently, we demonstrated that the addition of PANI could obviously improve the electrocatalytic activity and durability of Pd catalysts. ${ }^{57}$ Therefore, by combining the merits of bimetallic PtPd, conducting polymers and nanotube arrays (NTAs), novel electrocatalysts with low

\footnotetext{
${ }^{1} \mathrm{MOE}$ Laboratory of Bioinorganic and Synthetic Chemistry, KLGHEl of Environment and Energy Chemistry, School of Chemistry and Chemical Engineering, Instrumental Analysis and Research Centre, Sun Yat-sen University, Guangzhou, China

2These authors contributed equally to this work.

Correspondence: Professor G-R Li, MOE Laboratory of Bioinorganic and Synthetic Chemistry, KLGHEl of Environment and Energy Chemistry, School of Chemistry and Chemical Engineering, Instrumental Analysis and Research Centre, Sun Yat-sen University, No. 135, Xin-Gang West Road, Guangzhou 510275, China.

E-mail: ligaoren@mail.sysu.edu.cn
}

Received 3 July 2013; revised 6 August 2013; accepted 19 August 2013 
cost and high catalytic activity and durability can be designed and fabricated because of special synergistic effects and shape effects. However, to date, almost no studies have focused on this challenge.

Based on the above considerations, in this study, we developed novel PPy functionalized PtPd electrocatalysts based on PtPd/PPy/ PtPd three-layered nanotube arrays (TNTAs) for the electrooxidation of small organic molecules such as methanol, ethanol and formic acid, which are superior fuels for direct alcohol fuel cells (DAFCs) or direct formic acid fuel cells (DFAFCs). The motivation for designing such $\mathrm{PtPd} / \mathrm{PPy} / \mathrm{PtPd}$ TNTAs are as follows: (i) the interactions of PPy layers with PtPd layers would alter the electronic states of Pt and Pd atoms, leading to synergistic effects for catalytic reactions; (ii) the special PtPd/PPy/PtPd TNTAs would relax the transport of active species because of the hollow nanotube array structures, and the double thin layers of PtPd in the TNTAs would enable fast electrocatalytic reactions and provide short diffusion paths for the electroactive species; (iii) the PtPd/PPy/PtPd TNTAs would obviously enhance the utilization rate of electrocatalysts because of the hollow structure, array structure and anisotropic morphology; and (iv) PtPd/ PPy/PtPd TNTAs that are directly grown onto a conductive substrate provide excellent electrical contact with the current collectors, which would enable each $\mathrm{PtPd} / \mathrm{PPy} / \mathrm{PtPd}$ nanotube to effectively participate in catalytic reactions and eliminate almost all of the 'dead' volume. The electrochemical measurements confirmed that the designed PtPd/ PPy/PtPd TNTAs exhibit significantly enhanced electrocatalytic performance and long-term cycle stability compared with PtPd NTAs as well as the commercial $\mathrm{Pt} / \mathrm{C}$ and $\mathrm{Pd} / \mathrm{C}$ catalysts. To our knowledge, this is the first study of electrooxidation of small organic molecules on $\mathrm{PtPd} / \mathrm{PPy} / \mathrm{PtPd}$ TNTAs.

\section{MATERIALS AND METHODS}

\section{Synthesis of PtPd/PPy/PtPd TNTAs}

All chemical reagents were analytical (AR) grade. Electrochemical synthesis was performed in a simple three-electrode electrolytic cell via galvanostatic electrodeposition, and a graphite electrode was used as the counter electrode (spectral grade, $1.8 \mathrm{~cm}^{2}$ ). The saturated calomel electrode (SCE) was used as the reference electrode, which was connected to the cell with a double salt bridge system. The $\mathrm{PtPd} / \mathrm{PPy} / \mathrm{PtPd} \mathrm{TNTAs}$ were fabricated using the following procedures:

(1) $\mathrm{A} \mathrm{ZnO}$ nanorod array template was electrodeposited in a solution of $0.01 \mathrm{M} \mathrm{Zn}\left(\mathrm{NO}_{3}\right)_{2}+0.05 \mathrm{M} \quad \mathrm{NH}_{4} \mathrm{NO}_{3}$ with a current density of $0.5 \mathrm{mAcm}^{-2}$ at $70^{\circ} \mathrm{C}$ for $90 \mathrm{~min}$. Ti plates $\left(99.99 \%, 1.5 \mathrm{~cm}^{2}\right)$ were used as the substrate for electrodeposition, which were prepared using the following steps before each experiment: first, they were polished by $\mathrm{SiC}$ abrasive paper with coarseness ranging from 300 to 800 grits; then, they were dipped in $\mathrm{HCl}$ solution (5\%) for $10 \mathrm{~min}$, rinsed with acetone in an ultrasonic bath for $5 \mathrm{~min}$ and finally washed with distilled water.

(2) ZnO@PtPd core-shell nanorod arrays were prepared by the electrodeposition of PtPd onto the surfaces of $\mathrm{ZnO}$ nanorods in a solution of $1.0 \times$ $10^{-3} \mathrm{M} \mathrm{H}_{2} \mathrm{PtCl}_{6}+0.6 \times 10^{-3} \mathrm{M} \mathrm{PdCl}_{2}+1.0 \times 10^{-3} \mathrm{M} \mathrm{NaH}_{2} \mathrm{PO}_{2} \cdot \mathrm{H}_{2} \mathrm{O}+$ $0.2 \times 10^{-3} \mathrm{M} \mathrm{C}_{6} \mathrm{H}_{5} \mathrm{Na}_{3} \mathrm{O}_{7} \cdot 2 \mathrm{H}_{2} \mathrm{O}$ (the pH value was controlled to $4.0 \pm 0.2$ with $\mathrm{NaOH}$ ) with a current density of $0.25 \mathrm{~mA} \mathrm{~cm}^{-2}$ at $30^{\circ} \mathrm{C}$ for $35 \mathrm{~min}$.

(3) PPy layers were electrodeposited onto the surfaces of $\mathrm{ZnO@PtPd} \mathrm{nanorod}$ arrays to form ZnO@PtPd@PPy in a solution of $0.01 \mathrm{M}$ pyrrole $+0.05 \mathrm{M}$ $\mathrm{Na}_{2} \mathrm{SO}_{4}$ by galvanostatic electrolysis at $1.0 \mathrm{~mA} \cdot \mathrm{cm}^{-2}$ for $30 \mathrm{~min}$ at $70{ }^{\circ} \mathrm{C}$.

(4) PtPd layers were further electrodeposited onto the surfaces of ZnO@PtPd@PPy nanorods to form ZnO@PtPd@PPy@PtPd nanorods in a solution of $1.0 \times 10^{-3} \mathrm{M} \mathrm{H}_{2} \mathrm{PtCl}_{6}+0.6 \times 10^{-3} \mathrm{M} \mathrm{PdCl}_{2}+1.0 \times 10^{-3} \mathrm{M}$ $\mathrm{NaH}_{2} \mathrm{PO}_{2} \cdot \mathrm{H}_{2} \mathrm{O}+0.2 \times 10^{-3} \mathrm{M} \mathrm{C}_{6} \mathrm{H}_{5} \mathrm{Na}_{3} \mathrm{O}_{7} \cdot 2 \mathrm{H}_{2} \mathrm{O}$ (the $\mathrm{pH}$ value was controlled to $4.0 \pm 0.2$ with $\mathrm{NaOH}$ ) with a current density of $0.25 \mathrm{~mA} \cdot \mathrm{cm}^{-2}$ at $30^{\circ} \mathrm{C}$ for $35 \mathrm{~min}$.

(5) The synthesized ZnO@PtPd@PPy@PtPd nanorod arrays were immersed in a $3 \% \mathrm{NH}_{3} \cdot \mathrm{H}_{2} \mathrm{O}$ solution for $2 \mathrm{~h}$ to completely remove the $\mathrm{ZnO}$ nanorod array template, and the PtPd/PPy/PtPd TNTAs were finally fabricated. The fabricated PtPd/PPy/PtPd TNTAs were washed with doubly deionized $\mathrm{H}_{2} \mathrm{O}$ several times.

\section{Characterization of the PtPd/PPy/PtPd TNTAs}

The morphologies of the synthesized PtPd/PPy/PtPd TNTAs were characterized using a field-emission scanning electron microscope (FE-SEM, JSM-6330F), a transmission electron microscope (TEM, JEM-2010HR) and a high-angle annular dark-field scanning TEM (HAADF-STEM, FEI Tecnai G2 F30). The chemical composition of the PtPd/PPy/PtPd TNTAs was characterized by energy-dispersive X-ray spectroscopy (EDS, INCA 300) and X-ray photoelectron spectroscopy (XPS, ESCALAB 250). All XPS spectra were corrected using the $\mathrm{C} 1 \mathrm{~s}$ line at $284.6 \mathrm{eV}$. Curve fitting and background subtraction were used.

\section{Electrochemical measurements}

Cyclic voltammetry and chronoamperometry measurements were performed on a $\mathrm{CHI} 760 \mathrm{D}$ electrochemical workstation ( $\mathrm{CH}$ instruments, Inc.) with a standard three-electrode electrolytic cell. A Pt foil served as the counter electrode. A SCE was used as the reference electrode (in this paper, all potentials were the values vs SCE). Prior to performing the measurements, the electrolyte solution was purged with high-purity nitrogen gas for at least $10 \mathrm{~min}$. All electrochemical measurements were performed at $25 \pm 3{ }^{\circ} \mathrm{C}$. PtPd/ $\mathrm{PPy} / \mathrm{PtPd}$ TNTAs grown on a Ti substrate served as the working electrode. Before the electrochemical measurements were performed, the surfaces of the PtPd/PPy/PtPd TNTAs were covered by $10 \mu \mathrm{l}$ of Nafion ( $5 \mathrm{wt} \%$ ) solution. The electrodes, with commercial $\mathrm{Pt} / \mathrm{C}$ catalysts used as working electrodes, were prepared as follows: a glassy carbon electrode (diameter of $4 \mathrm{~mm}$ and an apparent surface area of $0.1256 \mathrm{~cm}^{2}$ ) was polished with 0.3 and $0.05 \mu \mathrm{m} \mathrm{Al} \mathrm{O}_{3}$ sequentially and then washed with doubly deionized $\mathrm{H}_{2} \mathrm{O}$ three times. Eight milligrams of $\mathrm{Pt} / \mathrm{C}$ catalyst $(20 \% \mathrm{Pt}$ on Vulcan XC-72, JM) and $2 \mathrm{ml}$ of $\mathrm{C}_{2} \mathrm{H}_{5} \mathrm{OH}$ were mixed to obtain the catalyst slurry. Then, $8.5 \mu \mathrm{l}$ of slurry was uniformly spread onto the surface of the glassy carbon electrode. After drying, $4.5 \mu \mathrm{l}$ of Nafion (5.0 wt.\%) solution was applied to cover the surface of the catalyst layer, thus completing the fabrication of the working electrode of commercial Pt/C (Pt loading: $54 \mu \mathrm{g} \mathrm{cm}^{-2}$ ). The electrodes with commercial $\mathrm{Pd} / \mathrm{C}$ used as working electrodes were prepared by the same procedure described above (Pd loading: $24 \mu \mathrm{g} \mathrm{cm}^{-2}$ ). CV curves of methanol, ethanol and formic acid oxidation reactions were recorded between -0.20 and $1.00 \mathrm{~V}$ vs SCE at a scan rate of $100 \mathrm{mV} \mathrm{s}^{-1}$. Chronoamperometry curves of methanol, ethanol and formic acid oxidation reactions were measured at $0.55,0.65$ and $0.20 \mathrm{~V}$. For the above $\mathrm{CV}$ and chronoamperometry measurements, a solution of $0.5 \mathrm{M} \mathrm{CH}_{3} \mathrm{OH}+0.5 \mathrm{M} \mathrm{H}_{2} \mathrm{SO}_{4}$ was used for the methanol oxidation reaction, a solution of $0.5 \mathrm{M} \mathrm{CH}_{3} \mathrm{CH}_{2} \mathrm{OH}+0.5 \mathrm{M} \mathrm{H}_{2} \mathrm{SO}_{4}$ was used for the ethanol oxidation reaction and a solution of $0.5 \mathrm{M} \mathrm{HCOOH}+0.5 \mathrm{M} \mathrm{H}_{2} \mathrm{SO}_{4}$ was used for the formic acid oxidation reaction. Prior to all experiments, the electrolyte solution was purged with high-purity nitrogen gas for $10 \mathrm{~min}$. All electrochemical measurements were performed at room temperature $\left(25 \pm 3^{\circ} \mathrm{C}\right)$.

\section{RESULTS AND DISCUSSION}

The schematic illustration of the procedures utilized to fabricate $\mathrm{PtPd} / \mathrm{PPy} / \mathrm{PtPd}$ TNTAs is shown in Figure 1. After the fabrication of the $\mathrm{ZnO}$ nanorod arrays (NRAs), PtPd layers were then electrodeposited onto the surfaces of the $\mathrm{ZnO}$ nanorods to form $\mathrm{PtPd} / \mathrm{ZnO}$ NRAs. PPy layers were further electrodeposited onto the surfaces of the PtPd/ZnO NRAs to form PPy/PtPd/ZnO NRAs. Next, the PtPd layers were further electrodeposited onto the surfaces of the PPy/ $\mathrm{PtPd} / \mathrm{ZnO}$ NRAs to form PtPd/PPy/PtPd/ZnO NRAs. Finally, the $\mathrm{PtPd} / \mathrm{PPy} / \mathrm{PtPd}$ TNTAs were fabricated by dissolving the $\mathrm{ZnO}$ nanorods from the PtPd/PPy/PtPd/ZnO NRAs in a $0.5 \mathrm{M} \mathrm{NaOH}$ solution. The details of the fabrication procedures are described in the experimental section in the supporting information. SEM images of the synthesized $\mathrm{ZnO}, \mathrm{PtPd} / \mathrm{ZnO}, \mathrm{PPy} / \mathrm{PtPd} / \mathrm{ZnO}$ and $\mathrm{PtPd} / \mathrm{PPy} / \mathrm{PtPd} /$ $\mathrm{ZnO}$ NRAs are shown in Figures $2 \mathrm{a}-\mathrm{d}$, respectively. A typical SEM 


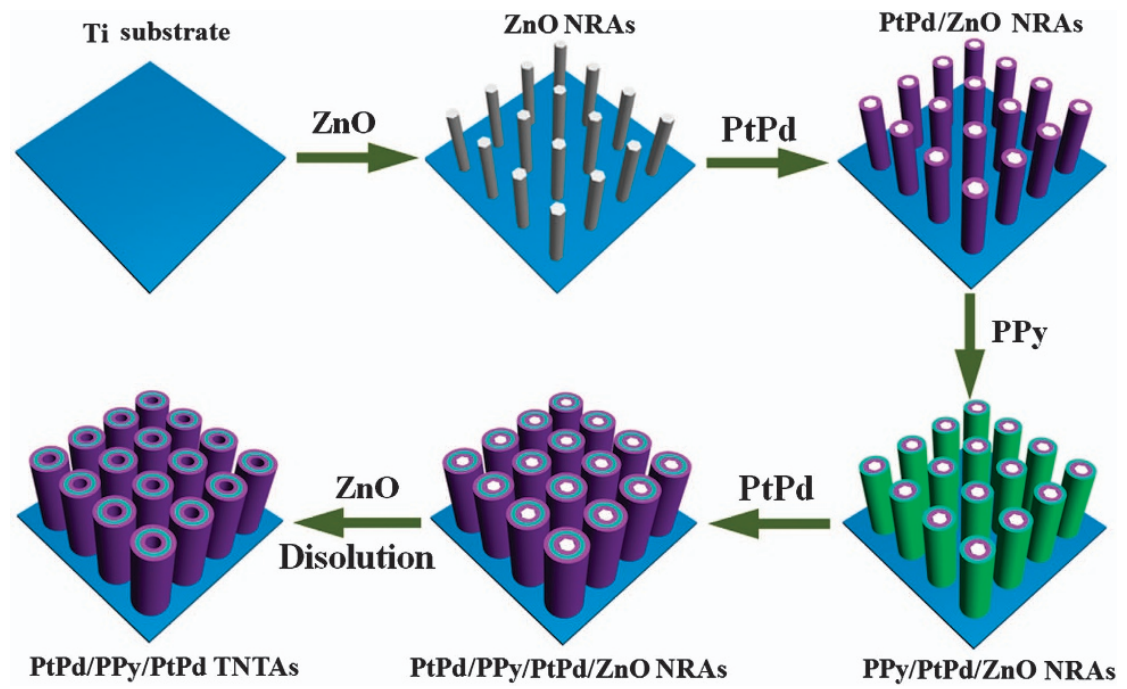

Figure 1 Schematic illustration of the fabrication process of the PtPd/PPy/PtPd TNTAs.
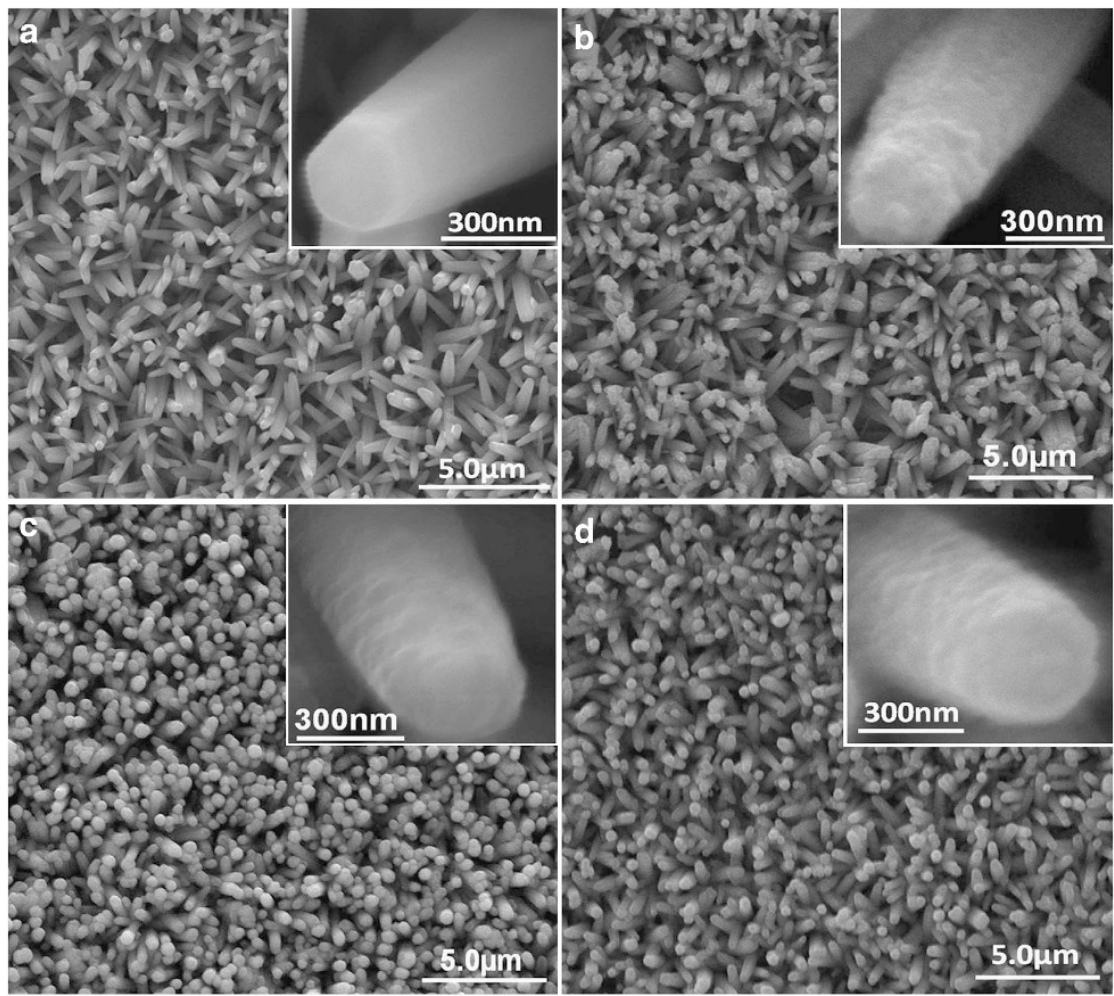

Figure 2 SEM images of the fabricated (a) ZnO NRAs, (b) PtPd/ZnO NRAs, (c) PPy/PtPd/ZnO NRAs and (d) PtPd/PPy/PtPd/ZnO NRAs.

image of the fabricated PtPd/PPy/PtPd TNTAs is shown in Figure 3a. The nanotubes are separated from each other, and the high density of voids in the volume of material can be clearly observed; thus, an excellent three-dimensional (3D) space for the mass transfer of reactant and resultant molecules exists in the PtPd/PPy/PtPd TNTAs. The lengths of the PtPd/PPy/PtPd nanotubes are approximately $2 \mu \mathrm{m}$. A typical TEM image of the PtPd/PPy/PtPd TNTAs is shown in Figure $3 \mathrm{~b}$, which indicates that the $\mathrm{PtPd} / \mathrm{PPy} / \mathrm{PtPd}$ TNTAs have a homogeneous wall thickness of approximately $60 \mathrm{~nm}$ and an inner diameter of approximately $200 \mathrm{~nm}$. To verify the sandwich-like nanostructures in the PtPd/PPy/PtPd TNTAs, a TEM image of the frontal view of a PtPd/PPy/PtPd nanotube is shown in Figure 3c, which reveals the sandwich-like structures and indicates the successful fabrication of PtPd/PPy/PtPd TNTAs. The magnified TEM image of the PtPd layers in the marked red area in Figure $3 \mathrm{c}$ is shown in Figure 3d, which indicates that the PtPd layers consist of nanocrystals of a size ranging from 3 to $4 \mathrm{~nm}$. The magnified TEM image of the middle PPy layers in the marked green area in Figure $3 \mathrm{c}$ is shown in Supplementary Figure S1, which indicates that the PPy layers are amorphous. The unique sandwich-like structures in the $\mathrm{PtPd} / \mathrm{PPy} /$ PtPd TNTAs enable the electroactive species to have complete access to the catalysts, thus enabling the PtPd layers to efficiently participate 


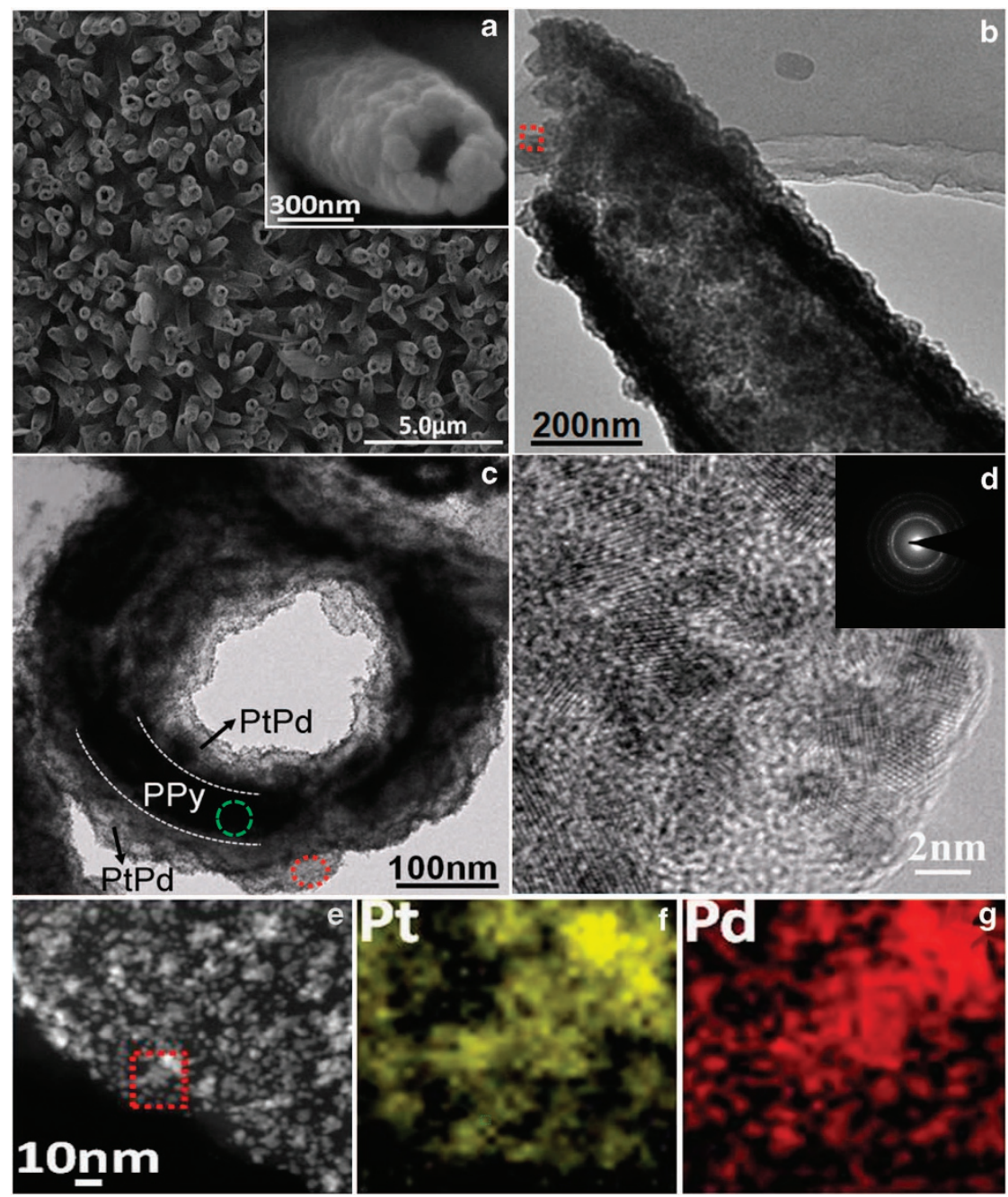

Figure 3 (a) SEM image of the PtPd/PPy/PtPd TNTAs; (b) TEM image of a typical PtPd/PPy/PtPd nanotube; (c) TEM image of a frontal PtPd/PPy/PtPd nanotube; (d) HRTEM image of the area marked red in (c); (e) HAADF-STEM image of the marked area in (b); (f) Pt elemental mapping image of the marked area in (e); (g) Pd elemental mapping image of the marked area in (e).

in the electrocatalytic reactions. For comparison, PtPd nanotube arrays (NTAs) were also synthesized by a similar method, and an SEM image of some representative NTAs is shown in Supplementary Figure S2.

To further study the PtPd layers in PtPd/PPy/PtPd TNTAs, highangle annular dark-field scanning TEM (HAADF-STEM) images were obtained in the marked area in Figure $3 \mathrm{~b}$ and a typical HAADFSTEM image is shown in Figure 3e, which reveals the dispersed PtPd nanocrystals of a size of approximately $4 \mathrm{~nm}$. EDX mapping was performed in the marked area in Figure $3 \mathrm{e}$ to characterize the distributions of $\mathrm{Pt}$ and $\mathrm{Pd}$. The corresponding EDX maps for elements of $\mathrm{Pt}$ and $\mathrm{Pd}$ are shown in Figures $3 \mathrm{f}$ and $\mathrm{g}$, respectively, which indicate that the elements of $\mathrm{Pt}$ and $\mathrm{Pd}$ both are well dispersed in the PtPd layers. The $\mathrm{Pt} / \mathrm{Pd}$ atomic ratio in the $\mathrm{PtPd} / \mathrm{PPy} / \mathrm{PtPd}$ TNTAs was determined to be approximately 57/43. The XRD pattern of the PtPd/PPy/PtPd TNTAs is shown in Figure $4 \mathrm{a}$, and no peak is observed other than the peaks of the Ti substrate. This lack of response can be attributed to the small size of the PtPd nanocrystals and the amorphous PPy layers in the sample.

Fourier transform IR spectroscopy (FTIR) spectra of the PtPd/PPy/ PtPd TNTAs and PPy NTAs are shown in Figure 4b. For the PPy
NTAs, the strong peak at approximately $1109 \mathrm{~cm}^{-1}$ indicates the doping state of PPy, and the broad band at $3000-3500 \mathrm{~cm}^{-1}$ is attributed to the $\mathrm{C}-\mathrm{H}$ and $\mathrm{N}-\mathrm{H}$ stretching vibrations of $\mathrm{PPy} .{ }^{55-56,58-60}$ The peak at $1263 \mathrm{~cm}^{-1}$ is attributed to the $\mathrm{C}-\mathrm{N}$ stretching vibrations of PPy. ${ }^{61}$ The PtPd/PPy/PtPd TNTAs exhibit a similar FTIR spectrum to that of the PPy films, as shown in Figure $4 \mathrm{~b}$. The differences between the FTIR spectra of the PtPd/PPy/PtPd TNTAs and the PPy NTAs are the shift in the characteristic bands to higher wave numbers and the stronger peak intensities for the PtPd/PPy/PtPd TNTAs, which suggests the presence of electron interactions between the PPy layers and the PtPd nanocrystals.

To investigate the effects of PPy on the electron structures of Pt and $\mathrm{Pd}$, XPS spectra of PtPd/PPy/PtPd TNTAs and PtPd NTAs in the Pt $4 f, \mathrm{Pd} 3 d$ and $\mathrm{N} 2 p$ regions were measured. For every sample, the $\mathrm{Pt} 4 f$ peak can be deconvolved into two pairs of doublets, as shown in Figure 5a-b. A comparison of the relative areas of the integrated intensity of the $\mathrm{Pt}^{0}$ and $\mathrm{Pt}^{\mathrm{II}}$ peaks in Figure $5 \mathrm{a}$ indicates that most of the Pt exists as $\mathrm{Pt}^{\mathrm{II}}$ in the PtPd NTAs, whereas much less $\mathrm{Pt}^{\mathrm{II}}$ exists in the PtPd/PPy/PtPd TNTAs, as shown in Figure 5b; thus, the introduction of PPy can significantly decrease the content of $\mathrm{Pt}^{\mathrm{II}}$ and increase the relative content of $\mathrm{Pt}^{0}$ in $\mathrm{PtPd} / \mathrm{PPy} / \mathrm{PtPd}$ TNTAs. 


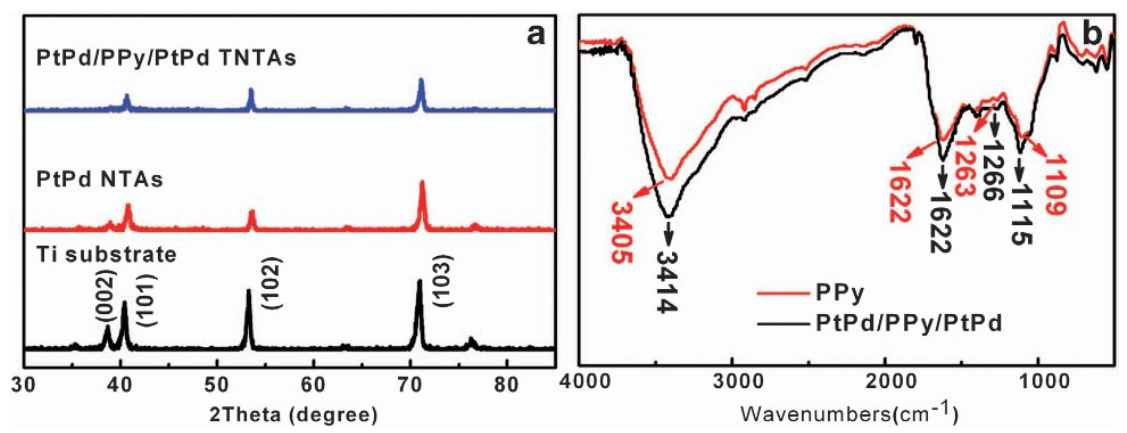

Figure 4 (a) XRD patterns of the Ti substrate, PtPd NTAs and PtPd/PPy/PtPd TNTAs; (b) FT-IR spectra of the PPy NTAs and the PtPd/PPy/PtPd TNTAs.
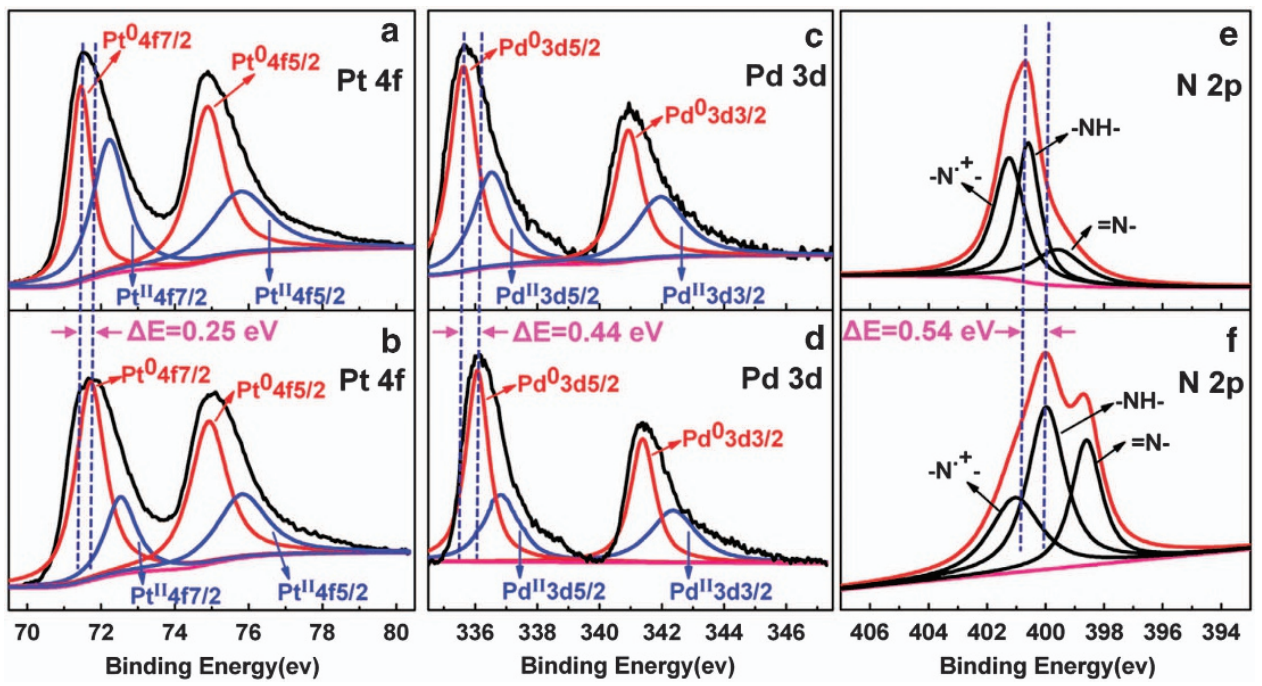

Figure 5 XPS spectra of Pt $4 f$ of the (a) PtPd NTAs and (b) PtPd/PPy/PtPd TNTAs; XPS spectra of Pd $3 d$ of (c) PtPd NTAs and (d) PtPd/PPy/PtPd TNTAs; and XPS spectra of N $2 p$ of (e) PPy NTAs and (f) PtPd/PPy/PtPd TNTAs.

In addition, we observed a definite positive shift of $\sim 0.25 \mathrm{eV}$ in the binding energy of $\mathrm{Pt} 4 f$ in the PtPd/PPy/PtPd TNTAs relative to that in the PtPd NTAs, indicating the change of the electronic states of the Pt atoms. For the PtPd/PPy/PtPd TNTAs and the PtPd NTAs, the Pd $3 d$ peak can also be deconvolved into two pairs of doublets, as shown in Figures $5 c$ and d. A comparison of the integrated intensities of the $\mathrm{Pd}^{0}$ and $\mathrm{Pd}^{\mathrm{II}}$ peaks in Figure $5 \mathrm{c}$ indicates that more $\mathrm{Pd}$ exists as $\mathrm{Pd}^{0}$ in the $\mathrm{Pd} / \mathrm{PPy} / \mathrm{Pd}$ TNTAs and that less $\mathrm{Pd}^{\mathrm{II}}$ is present, that is, the relative content of $\mathrm{Pd}^{0}$ in the $\mathrm{PtPd} / \mathrm{PPy} / \mathrm{PtPd}$ TNTAs increased. The $\mathrm{Pd} 3 d$ peaks of the PtPd/PPy/PtPd TNTAs shifted by approximately $0.44 \mathrm{eV}$ to higher binding energies relative to those of the PtPd NTAs, indicating the change of the electronic states of the Pd atoms. The XPS spectra of the PtPd/PPy/PtPd TNTAs and the PPy NTAs in the N $2 p$ regions are shown in Figures $5 \mathrm{e}$ and $\mathrm{f}$, respectively; compared with the PPy NTAs, the PtPd/PPy/PtPd TNTAs exhibit a much higher content of $=\mathrm{N}-$. We also observed a definite positive shift of $\sim 0.55 \mathrm{eV}$ in the binding energy of $-\mathrm{NH}-$ for the $\mathrm{PtPd} / \mathrm{PPy} / \mathrm{PtPd}$ TNTAs relative to the PPy NTAs. Therefore, the above shifts in binding energy of the $\mathrm{Pt} 4 f, \mathrm{Pd} 3 d$ and $\mathrm{N} 2 p$ peaks confirm the presence of electron interactions among Pt, Pd and PPy in the PtPd/ PPy/PtPd TNTAs, which lead to a higher content of metallic Pt and $\mathrm{Pd}$ and to synergistic effects for electrocatalytic reactions.

The electrocatalytic activity of the PtPd/PPy/PtPd TNTAs and of the PtPd NTAs and Pt/C catalysts towards methanol oxidation was studied in a solution of $0.5 \mathrm{M} \mathrm{CH}_{3} \mathrm{OH}+0.5 \mathrm{M} \mathrm{H}_{2} \mathrm{SO}_{4}$, and the CVs at $100 \mathrm{mV} \mathrm{s}^{-1}$ are shown in Figure $6 \mathrm{a}$; the specific electroactivity of $\mathrm{PtPd} / \mathrm{PPy} / \mathrm{PtPd}$ TNTAs was $\sim 4.5$ times and $\sim 5.2$ times higher than that of the PtPd NTAs and the Pt/C catalysts, respectively. (The current densities all are normalized to the electrochemically active surface area (ECSA).) The PtPd/PPy/PtPd TNTAs also exhibited an obviously lower onset potential of the forward anodic peak than those of the PtPd NTAs and Pt/C catalysts, as shown in Figure 6b, indicating that they are more favorable for methanol electrooxidation. In addition, the onset potential of the backward scan peak of the $\mathrm{PtPd} / \mathrm{PPy} / \mathrm{PtPd}$ TNTAs obviously shifted positively relative to those of the PtPd NTAs and the commercial Pt/C catalyst, as shown in Figure $6 \mathrm{c}$. It is well known that the backward anodic peak is attributed to the continuous oxidation of incompletely oxidized carbonaceous intermediates, such as $\mathrm{CO}, \mathrm{HCOO}^{-}$, and $\mathrm{HCO}^{-}$, accumulated on the surfaces of the catalysts during methanol oxidation. ${ }^{62}$ Therefore, the positive shift of the onset potential of the backward scan peak suggests the weakened chemisorption of the intermediate species on the PtPd/ PPy/PtPd TNTAs, which will facilitate the removal of the adsorbed intermediate species to generate clean and active surface sites, thereby enhancing the electroactivity and durability of the PtPd/PPy/PtPd TNTAs.

The CVs of the PtPd/PPy/PtPd TNTAs with an increasing cycle number are shown in Figure 6d, and the corresponding change of the 

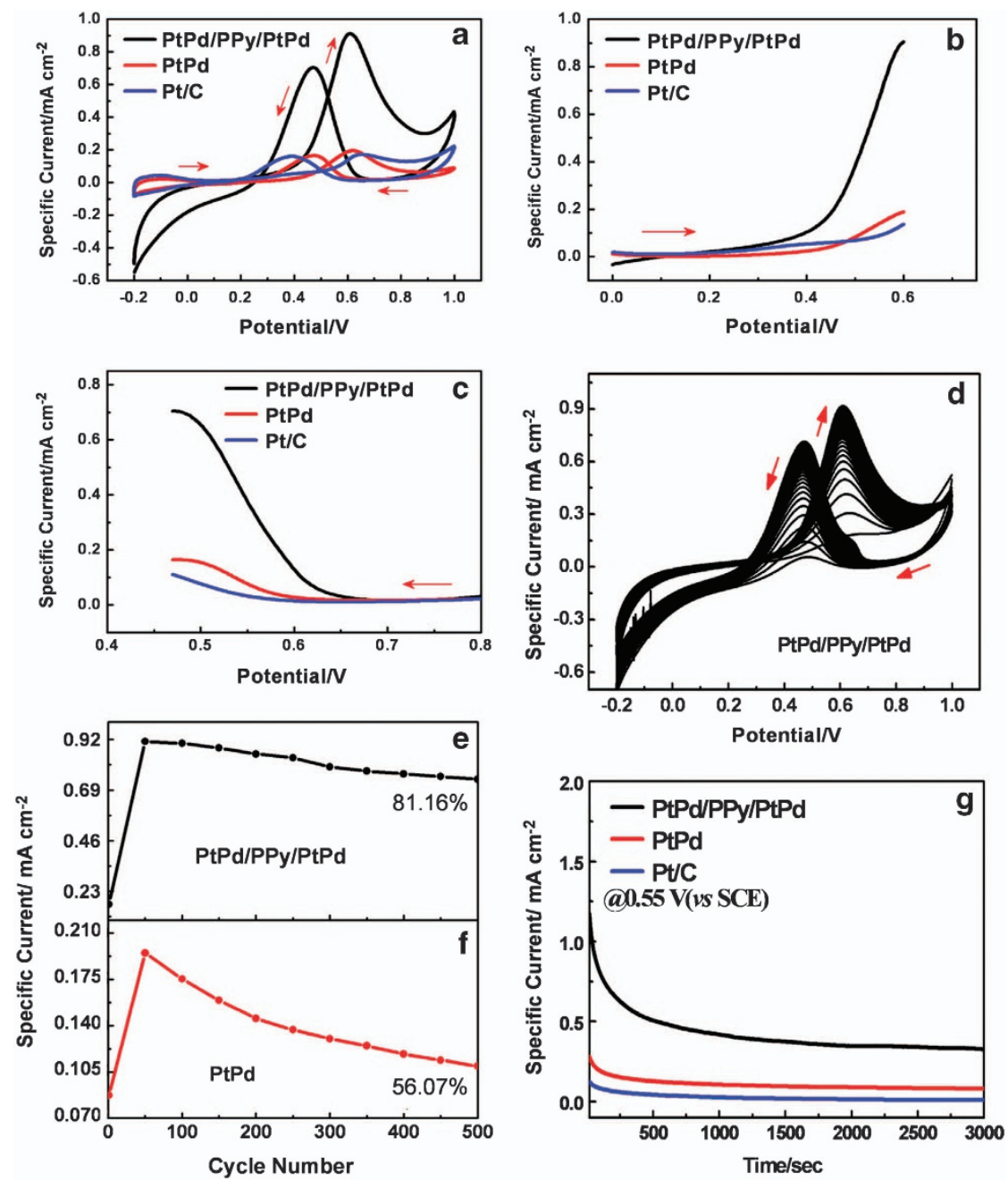

Figure 6 (a) CVs of the PtPd/PPy/PtPd TNTAs, PtPd NTAs and commercial Pt/C catalysts in a solution of $0.5 \mathrm{M} \mathrm{CH}_{3} \mathrm{OH}+0.5 \mathrm{M} \mathrm{H}_{2} \mathrm{SO}_{4}$ at $100 \mathrm{mVs}^{-1}$; (b) the magnified forward scan peaks of the CVs in (a); (c) the magnified backward scan peaks of CVs in (a); (d) CVs of the PtPd/PPy/PtPd TNTAs from the 1 st to the 500th cycle; (e, f) The change of the peak current density with increasing cycle number for the (e) PtPd/PPy/PtPd TNTAs and (f) PtPd NTAs; (g) chronoamperometry curves of the PtPd/PPy/PtPd TNTAs, PtPd NTAs and commercial Pt/C catalysts in a solution of $0.5 \mathrm{M} \mathrm{H} \mathrm{H}_{2} \mathrm{SO}_{4}+0.5 \mathrm{M} \mathrm{CH} \mathrm{OH}_{3}$ at $100 \mathrm{mVs}^{-1}$.

peak current density is shown in Figure 6e. At the initial cycles, the peak current density of the PtPd/PPy/PtPd TNTAs drastically increases, and the maximum peak current density appears at approximately the 50th cycle. After 50 cycles, the peak current density exhibits a slow attenuation with further increases in the cycle number. After 500 cycles, the conservation rate of the peak current density is $\sim 81.16 \%$ of the maximum value, indicating that the $\mathrm{PtPd} / \mathrm{PPy} / \mathrm{PtPd}$ TNTAs have good cycle stability for methanol electrooxidation. However, the peak current density of the PtPd NTAs exhibits a much lower conservation rate $(\sim 56.07 \%)$ of the maximum value than do the PtPd/PPy/PtPd TNTAs after 500 cycles, as shown in Figure 6f. Therefore, the PtPd/PPy/PtPd TNTAs exhibit a significantly enhanced cycle stability compared with the PtPd NTAs catalysts, indicating the positive role of $\mathrm{PPy}$ in performance enhancement of the PtPd catalysts.

To further evaluate the advantage of $\mathrm{PPy}$ in resisting surface poisoning of the electrocatalysts, the chronoamperometry curves of the PtPd/PPy/PtPd TNTAs, PtPd NTAs and Pt/C catalysts were measured in a solution of $0.5 \mathrm{M} \mathrm{CH}_{3} \mathrm{OH}+0.5 \mathrm{M} \mathrm{H}_{2} \mathrm{SO}_{4}$, as shown in Figure 6g. The potentials were held at $0.55 \mathrm{~V}$ during the measurements. Compared with the PtPd NTAs and Pt/C catalysts, the PtPd/PPy/PtPd TNTAs clearly exhibited a much higher current density over time and a much slower attenuation, indicating a much higher catalytic activity for methanol electrooxidation and a much higher tolerance to the carbonaceous species generated during methanol electrooxidation.

The above results demonstrate the high electrocatalytic activity and cycle stability of PtPd/PPy/PtPd TNTAs, and the structure of the $\mathrm{PtPd} / \mathrm{PPy} / \mathrm{PtPd}$ TNTAs enables the enhanced performance of catalysts. This enhancement may be attributed to the special shape effects and synergistic effects: first, the TNTAs, with a hollow structure, a sandwich-like structure, an array structure and anisotropic morphology, provide efficient diffusion paths for electroactive species, which significantly enhances the diffusion rate and intercalation of the electroactive species and the utilization rate of the catalyst; second, the electron delocalization among the Pt $4 f$ orbitals, the Pd $3 d$ orbitals and the PPy $\pi$-conjugated ligands in the PtPd/PPy/PtPd TNTAs will alter the electronic structures of $\mathrm{Pt}$ and $\mathrm{Pd}$ and lead to synergistic effects. The synergistic effects between the PPy layers and the PtPd nanocrystals markedly lower the onset potential of the forward anodic 
peak, positively shift the onset potential of the backward scan peak, and obviously enhance the electroactivity and durability of the PtPd/ $\mathrm{PPy} / \mathrm{PtPd}$ TNTAs, as shown in Figures 6a-g. The special shape effects and synergistic effects of the PtPd/PPy/PtPd TNTAs on catalytic reactions are illustrated in detail in Figure 7.

Herein, the designed PtPd/PPy/PtPd TNTAs also exhibited high electrocatalytic activity and durability for ethanol oxidation. Figure $8 \mathrm{a}$ shows the electrocatalytic activity of the PtPd/PPy/PtPd TNTAs towards ethanol oxidation compared with the PtPd NTAs and the $\mathrm{Pt} / \mathrm{C}$ catalysts in a solution of $0.5 \mathrm{M} \mathrm{CH}_{3} \mathrm{CH}_{2} \mathrm{OH}+0.5 \mathrm{M} \mathrm{H}_{2} \mathrm{SO}_{4}$. The $\mathrm{PtPd} / \mathrm{PPy} / \mathrm{PtPd}$ TNTAs exhibited $\sim 4.5$ times and 6.5 times higher specific electroactivity than that of the PtPd NTAs and the Pt/C catalysts, respectively. In addition, among the catalysts tested, the
PtPd/PPy/PtPd TNTAs exhibited the lowest onset potential of the forward anodic peak, indicating they are the most favorable catalysts for ethanol electrooxidation. Figure $8 \mathrm{~b}$ shows the CVs of the PtPd/ $\mathrm{PPy} / \mathrm{PtPd}$ TNTAs with increasing cycle number, and the corresponding change of peak current density is shown in Figure 8c. The peak current density of the PtPd/PPy/PtPd TNTAs drastically increases at the initial cycles, and the maximum peak current density appears at the 200th cycle. After 200 cycles, the peak current density nearly remains constant with further increases of the cycle number. After 500 cycles, the attenuation of the peak current density is only $\sim 4.19 \%$, indicating excellent cycle stability of the PtPd/PPy/PtPd TNTAs for ethanol oxidation. However, after 500 cycles, the PtPd NTAs exhibit much more severe attenuation of the peak current density

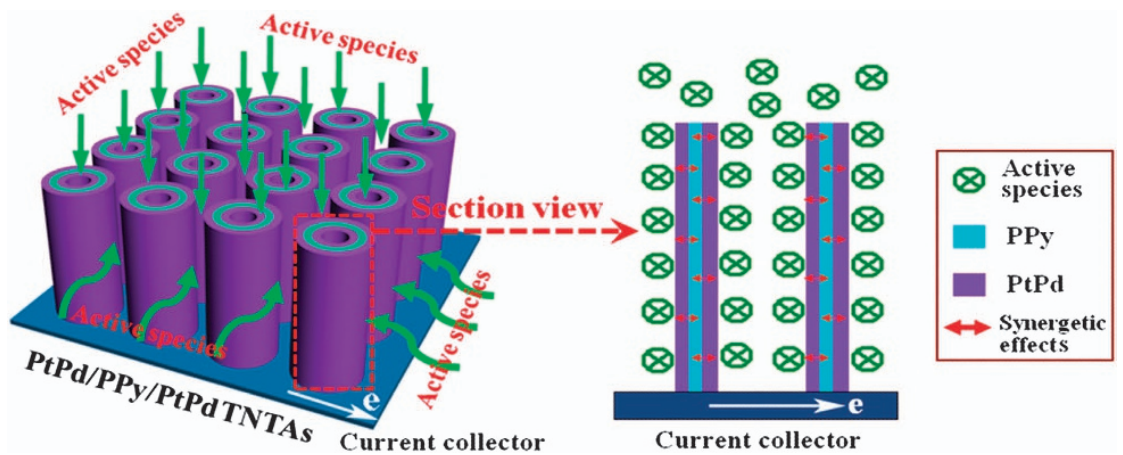

Figure 7 Nanotube array architectures and sandwich-structured walls in PtPd/PPy/PtPd TNTAs provide rapid transport and short diffusion paths for electroactive species; a large exposed surface for the efficient interaction with the electroactive species; and synergetic effects among Pt, Pd and PPy for electrocatalytic reactions.
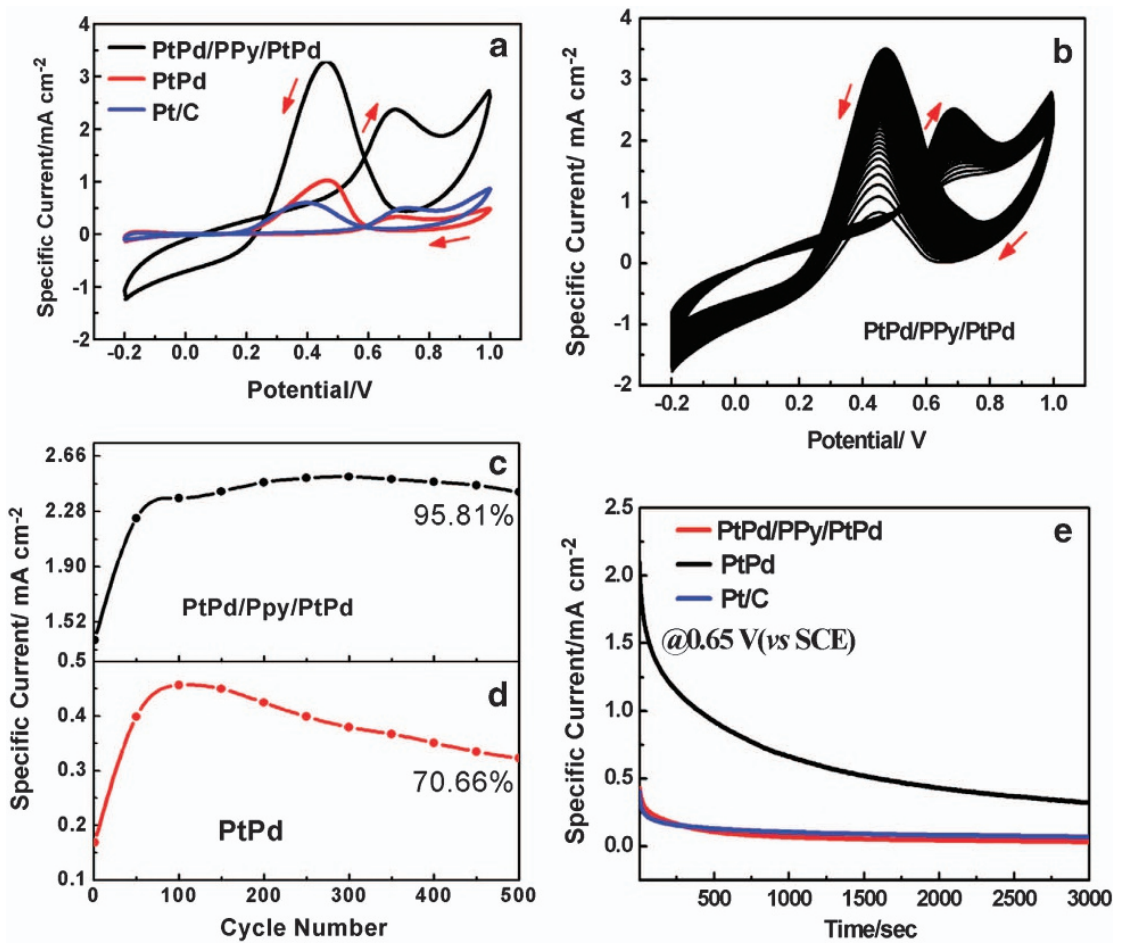

Figure 8 (a) CVs of the PtPd/PPy/PtPd TNTAs, PtPd NTAs and commercial Pt/C catalysts in a solution of $0.5 \mathrm{M} \mathrm{CH}_{3} \mathrm{CH}_{2} \mathrm{OH}+0.5 \mathrm{M} \mathrm{H}_{2} \mathrm{SO}_{4}$ at $100 \mathrm{mVs}$ (b) CVs of the PtPd/PPy/PtPd TNTAs from the 1st to the 500th cycle; (c, d) the change of the peak current density with increasing cycle number for the (c) PtPd/PPy/PtPd TNTAs and (d) PtPd NTAs; (e) chronoamperometry curves of the PtPd/PPy/PtPd TNTAs, PtPd NTAs and commercial Pt/C catalysts in a solution of $0.5 \mathrm{M} \mathrm{H}_{2} \mathrm{SO}_{4}+0.5 \mathrm{M} \mathrm{CH}_{3} \mathrm{CH}_{2} \mathrm{OH}$ at $100 \mathrm{mVs}^{-1}$. 

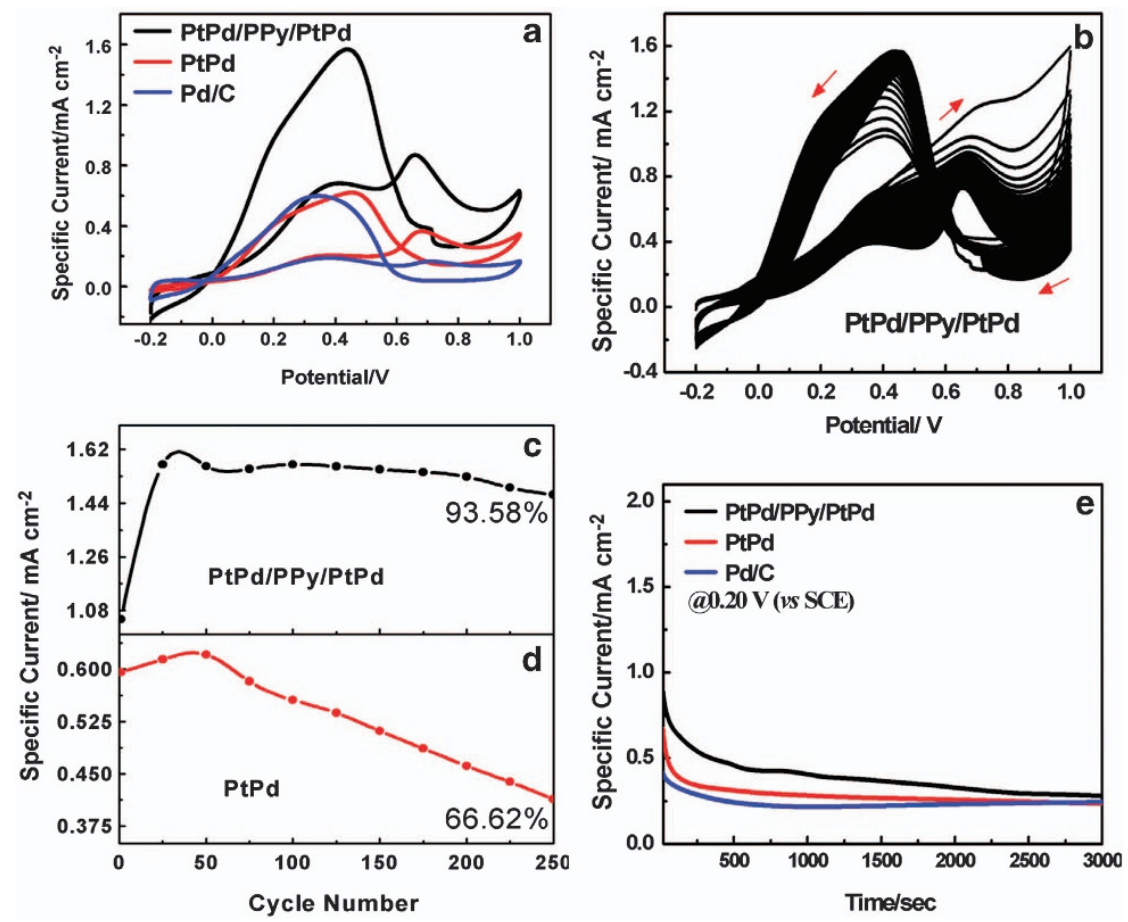

Figure 9 (a) $\mathrm{CVs}$ of the PtPd/PPy/PtPd TNTAs, PtPd NTAs and commercial Pd/C catalysts in a solution of $0.5 \mathrm{M} \mathrm{HCOOH}+0.5 \mathrm{M} \mathrm{H}_{2} \mathrm{SO}_{4}$ at $100 \mathrm{mVs}$; (b) CVs of the PtPd/PPy/PtPd TNTAs from the 1st to the 250th cycle; (c, d) the change of the peak current density with increasing cycle number for the (c) PtPd/PPy/PtPd TNTAs and (d) PtPd NTAs; (e) chronoamperometry curves of the PtPd/PPy/PtPd TNTAs, PtPd NTAs and commercial Pd/C catalysts in a solution of $0.5 \mathrm{M} \mathrm{H}_{2} \mathrm{SO}_{4}+0.5 \mathrm{M} \mathrm{HCOOH}$ at $100 \mathrm{mVs}^{-1}$.

( 29.34\%) than that of the PtPd/PPy/PtPd TNTAs, as shown in Figure 8d. Therefore, compared with the PtPd NTAs, the PtPd/PPy/ PtPd TNTAs exhibited significantly enhanced cycle stability as catalysts for ethanol electrooxidation. Figure 8e shows the chronoamperometry curves of the PtPd/PPy/PtPd TNTAs, PtPd NTAs and $\mathrm{Pt} / \mathrm{C}$ catalysts as measured in a solution of $0.5 \mathrm{M} \mathrm{CH}_{3} \mathrm{CH}_{2} \mathrm{OH}+0.5$ $\mathrm{M} \mathrm{H}_{2} \mathrm{SO}_{4}$. Compared with the PtPd NTAs and the commercial Pt/C catalysts, the PtPd/PPy/PtPd TNTAs exhibit significantly enhanced electrocatalytic activity over time and a much higher tolerance to the carbonaceous species generated during ethanol electrooxidation.

In addition, the designed PtPd/PPy/PtPd TNTAs exhibited high catalytic activity and cycle stability for formic acid electrooxidation. The electrocatalytic activity towards formic acid oxidation of the $\mathrm{PtPd} / \mathrm{PPy} / \mathrm{PtPd}$ TNTAs and of the PtPd NTAs and the Pd/C catalysts were studied in a solution of $0.5 \mathrm{M} \mathrm{HCOOH}+0.5 \mathrm{M} \mathrm{H}_{2} \mathrm{SO}_{4}$, as shown in Figure 9a, which indicates that the specific electroactivity of the PtPd/PPy/PtPd TNTAs is $\sim 2.4$ times and 5.0 times higher than those of the PtPd NTAs and the Pd/C catalysts, respectively. The CVs of the PtPd/PPy/PtPd TNTAs with an increasing cycle number are shown in Figure $9 \mathrm{~b}$, and the corresponding change of the peak current density is shown in Figure 9c. After 250 cycles, the attenuation of the peak current density of the PtPd/PPy/PtPd TNTAs is only $\sim 6.42 \%$, indicating excellent cycle stability of the PtPd/PPy/PtPd TNTAs for formic acid electrooxidation. In contrast, the PtPd NTAs exhibited a much more severe attenuation $(33.38 \%)$ of the peak current density than that of the PtPd/PPy/PtPd TNTAs after 250 cycles, as shown in Figure 9d. Therefore, the PtPd/PPy/PtPd TNTAs exhibited significantly improved cycle stability compared with that of the PtPd NTAs for formic acid electrooxidation. The chronoamperometry curves of the PtPd/PPy/PtPd TNTAs, PtPd NTAs and Pd/C catalysts in Figure $9 \mathrm{e}$ also indicate that, among the catalysts tested, the PtPd/
PPy/PtPd TNTAs have the highest catalytic activity for formic acid electrooxidation and the highest tolerance to the carbonaceous species generated during the oxidation of formic acid. In addition, compared with the PtPd/PPy/PtPd films and the PtPd/PPy two-layered nanotube arrays, the PtPd/PPy/PtPd TNTAs also exhibited high activity and durability for the electrooxidation of methanol, ethanol and formic acid, as shown in Supplementary Figures S3-S8.

\section{CONCLUSIONS}

In summary, we have designed and synthesized novel high-performance PPy functionalized PtPd electrocatalysts based on PtPd/PPy/ PtPd TNTAs for the electrooxidation of small organic molecules. The unique hollow structures, array structures and sandwich-like structures in the PtPd/PPy/PtPd TNTAs provide rapid transport via short diffusion paths for electroactive species and a large exposed surface area to enable efficient interaction with electroactive species. In particular, the unique sandwich-like structure of $\mathrm{PtPd} / \mathrm{PPy} / \mathrm{PtPd}$ in the sample results in both electron delocalization among the Pt $4 f$ orbitals, the Pd $3 d$ orbitals and the PPy $\pi$-conjugated ligands and electron transfer from PPy to the Pt and Pd atoms, leading to synergistic effects for catalytic reactions. Because of the above merits, the designed $\mathrm{PtPd} / \mathrm{PPy} / \mathrm{PtPd}$ TNTAs exhibit significantly improved catalytic activity and durability for the electrooxidation of small organic molecules compared with those of the PtPd NTAs and the commercial $\mathrm{Pt} / \mathrm{C}$ and $\mathrm{Pd} / \mathrm{C}$ catalysts. The design strategy for creating multi-walled composite nanotube arrays will pave the way towards the fabrication of new catalysts with high performance in the future.

\section{CONFLICT OF INTEREST}

The authors declare no conflict of interest. 


\section{ACKNOWLEDGEMENTS}

This work was supported by NSFC (51173212, 21073240, and 21273290), the Fundamental Research Fund for the Central Universities (13lgpy51), the Research Fund for New Star Scientists of the Pearl River Science and Technology of Guangzhou (2011J2200057), the Research Fund for the Doctoral Program of Higher Education of China (No. 20120171110043), SRF for ROCS, SEM ([2012]1707) and the Open-Ended Fund of State Key Lab of Physical Chemistry of Solid Surfaces of Xiamen University (201113).

1 Sanabria-Chinchilla, J., Asazawa, K., Sakamoto, T., Yamada, K., Tanaka, H. \& Strasser, P. Noble metal-free hydrazine fuel cell catalysts: EPOC effect in competing chemical and electrochemical reaction pathways. J. Am. Chem. Soc. 133, 5425-5431 (2011).

2 Wang, S., Iyyamperumal, E., Roy, A., Xue, Y., Yu, D. \& Dai, L. Vertically aligned BCN nanotubes as efficient metal-free electrocatalysts for the oxygen reduction reaction: synergetic effect by Co-doping with boron and nitrogen. Angew. Chem. Int. Ed. 50, 11756-11760 (2011).

3 Yang, L., Jiang, S., Zhao, Y., Zhu, L., Chen, S., Wang, X., Wu, Q., Ma, J., Ma, Y. \& Hu, Z. Boron-doped carbon nanotubes as metal-free electrocatalysts for the oxygen reduction reaction. Angew. Chem. Int. Ed. 50, 7132-7135 (2011).

4 Wang, H., Liang, Y., Li, Y. \& Dai, H. Co1-xS-graphene hybrid: a high-performance metal chalcogenide electrocata-lyst for oxygen reduction. Angew. Chem. Int. Ed. 50, 10969-10972 (2011).

5 Li, Y., Hasin, P. \& Wu, Y. NixCo3-xO4 nanowire arrays for electrocatalytic oxygen evolution. Adv. Mater. 22, 1926-1929 (2010).

6 Cui, C., Gan, L., Li, H.-H., Yu, S.-H., Heggen, M. \& Strasser, P. Octahedral PtNi nanoparticle catalysts: exceptional oxygen reduction activity by tuning the alloy particle surface composition. Nano Lett. 12, 5885-5889 (2012).

7 Xia, B. Y., Wu, H. B., Wang, X. \& Lou, X. W. One-Pot synthesis of cubic PtCu3 nanocages with enhanced electrocatalytic activity for the methanol oxidation reaction. J. Am. Chem. Soc. 134, 13934-13937 (2012).

8 Zhang, L., Li, N., Gao, F., Hou, L. \& Xu, Z. Insulin amyloid fibrils: an excellent platform for controlled synthesis of ultrathin superlong platinum nanowires with high electrocatalytic activity. J. Am. Chem. Soc. 134, 11326-11329 (2012).

9 Yamauchi, Y., Tonegawa, A., Komatsu, M., Wang, H., Wang, L., Nemoto, Y., Suzuki, N. \& Kuroda, K. Electrochemical synthesis of mesoporous Pt-Au binary alloys with tunable compositions for enhancement of electrochemical performance. J. Am. Chem. Soc. 134, 5100-5109 (2012)

$10 \mathrm{Ma}, \mathrm{X}$., Meng, H. Cai, M. \& Shen, P. K. Bimetallic carbide nanocomposite enhanced Pt catalyst with high activity and stability for the oxygen reduction reaction. J. Am. Chem. Soc. 134, 1954-1957 (2012).

11 Huang, X., Li, Y., Li, Y., Zhou, H., Duan, X. \& Huang, Y. Synthesis of PtPd bimetal nanocrystals with controllable shape, composition, and their tunable catalytic properties. Nano Lett. 12, 4265-4270 (2012).

12 Yang, H., Zhang, J., Sun, K., Zou, S. \& Fang, J. Enhancing by weakening: electrooxidation of methanol on Pt3Co and Pt nanocubes. Angew. Chem. Int. Edit. 49, 6848-6851 (2010).

13 Zhang, J. \& Fang, J. A general strategy for preparation of Pt 3d-transition metal (Co, Fe, Ni) nanocubes. J. Am. Chem. Soc. 131, 18543-18547 (2009).

14 Guo, S., Li, D., Zhu, H., Zhang, S., Markovic, N. M., Stamenkovic, V. \& Sun, S. FePt and $\mathrm{CoPt}$ nanowires as efficient catalysts for the oxygen reduction reaction. Angew. Chem. Int. Edit. 52, 3465-3468 (2013).

15 Zhang, S., Shao, Y., Yin, G. \& Lin, Y. Electrostatic self-assembly of a Pt-around-Au nanocomposite with high activity towards formic acid oxidation. Angew. Chem. Int. Edit. 49, 2211-2214 (2010)

16 Xu, D., Bliznakov, S., Liu, Z. Fang J. \& Dimitrov, N. Composition-dependent electrocatalytic activity of Pt-Cu nanocube catalysts for formic acid oxidation. Angew. Chem. Int. Edit. 49, 1282-1285 (2010).

17 Ye, H. \& Crooks, R. M. Effect of elemental composition of PtPd bimetallic nanoparticles containing an average of 180 atoms on the kinetics of the electrochemical oxygen reduction reaction. J. Am. Chem. Soc. 129, 3627-3633 (2007).

18 Kang, Y., Ye, X., Chen, J., Cai, Y., Diaz, R. E., Adzic, R. R., Stach, E. A. \& Murray, C. B. Design of Pt-Pd binary superlattices exploiting shape effects and synergistic effects for oxygen reduction reactions. J. Am. Chem. Soc. 135, 42-45 (2013).

19 Tan, T. L., Wang, L.-L., Johnson, D. D. \& Bai, K. A comprehensive search for stable Pt-Pd nanoalloy configurations and their use as tunable catalysts. Nano Lett. 12 4875-4880 (2012)

20 Huang, R., Wen, Y.-H., Zhu, Z.-Z. \& Sun, S.-G. Pt-Pd bimetallic catalysts: structural and thermal stabilities of core-shell and alloyed nanoparticles. J. Phys. Chem. C 116 , 8664-8671 (2012)

21 Yin, A.-X., Min, X.-Q., Zhang, Y.-W. \& Yan, C.-H. Shape-selective synthesis and facetdependent enhanced electrocatalytic activity and durability of monodisperse sub-10 nm Pt-Pd tetrahedrons and cubes. J. Am. Chem. Soc. 133, 3816-3819 (2011).

22 Sanchez, S. I., Small, M. W., Zuo, J. \& Nuzzo, R. G. Structural characterization of Pt-Pd and Pd-Pt core-shell nanoclusters at atomic resolution. J. Am. Chem. Soc. 131, 8683-8689 (2009)

23 Peng, Z. \& Yang, H. Synthesis and oxygen reduction electrocatalytic property of Pt-onPd bimetallic hetero-nanostructures. J. Am. Chem. Soc. 131, 7542-7543 (2009).
24 Lee, H., Habas, S. E., Somorjai, G. A. \& Yang, P. Localized Pd overgrowth on cubic Pt nanocrystals for enhanced electrocatalytic oxidation of formic acid. J. Am. Chem. Soc. $130,5406-5407$ (2008)

25 Zhang, H., Jin, M., Wang, J., Kim, M. J., Yang, D. \& Xia, Y. Nanocrystals composed of alternating shells of $\mathrm{Pd}$ and $\mathrm{Pt}$ can be obtained by sequentially adding different precursors. J. Am. Chem. Soc. 133, 10422-10425 (2011).

26 Wang, L., Nemoto, Y. \& Yamauchi, Y. Direct synthesis of spatially-controlled Pt-on-Pd bimetallic nanodendri-tes with superior electrocatalytic activity. J. Am. Chem. Soc. 133, 9674-9677 (2011).

27 Zhang, H., Jin, M., Wang, J., Li, W., Camargo, P. H. C., Kim, M. J., Yang, D., Xie, Z. \& $\mathrm{Xia}, \mathrm{Y}$. Synthesis of Pd-Pt bimetallic nanocrystals with a concave structure through a bromide-induced galvanic replacement reaction. J. Am. Chem. Soc. 133, 6078-6089 (2011).

28 Koenigsmann, C., Santulli, A. C., Gong, K., Vukmirovic, M. B., Zhou, W., Sutter, E., Wong, S. S. \& Adzic, R. R. Enhanced electrocatalytic performance of processed, ultrathin, supported $\mathrm{Pd}$-Pt core-shell nanowire catalysts for the oxygen reduction reaction. J. Am. Chem. Soc. 133, 9783-9795 (2011).

29 Tao, F., Grass, M. E., Zhang, Y., Butcher, D. R., Renzas, J. R., Liu, Z., Chung, J. Y., Mun, B. S., Salmeron, M. \& Somorjai, G. A. Reaction-driven restructuring of Rh-Pd and Pt-Pd core-shell nanoparticles. Science 322, 932-934 (2008).

30 Lim, B., Jiang, M., Camargo, P. H. C., Cho, E. C., Tao, J., Lu, X., Zhu, Y. \& Xia, Y. $\mathrm{Pd}-\mathrm{Pt}$ bimetallic nanoden-drites with high activity for oxygen reduction. Science $\mathbf{3 2 4}$, 1302-1305 (2009).

31 Vidal-Iglesias, F. J., Solla-Gullón, J., Herrero, E., Aldaz, A. \& Feliu, J. M. Pd adatom decorated (100) preferentially oriented Pt nanoparticles for formic acid electrooxidation. Angew. Chem. Int. Edit 49, 6998-7001 (2010)

32 Zhu, C., Guo, S. \& Dong, S. PdM (M = Pt, Au) bimetallic alloy nanowires with enhanced electrocatalytic activity for electro-oxidation of small molecules. Adv. Mater. 24, 2326-2331 (2012).

33 Yin, A.-X., Min, X.-Q., Zhu, W., Wu, H.-S., Zhang, Y.-W. \& Yan, C.-H. Multiply twinned Pt-Pd nanoicosahedrons as highly active electrocatalysts for methanol oxidation. Chem. Commun. 48, 543-545 (2012).

34 Rosseler, O., Louvet, A., Keller, V. \& Keller, N. Enhanced CO photocatalytic oxidation in the presence of humidity by tuning composition of Pd-Pt bimetallic nanoparticles supported on TiO2. Chem. Commun. 47, 5331-5333 (2011).

35 Guo, S., Dong, S. \& Wang, E. Ultralong Pt-on-Pd bimetallic nanowires with nanoporous surface: nanodendritic structure for enhanced electrocatalytic activity. Chem. Commun. 46, 1869-1871 (2010).

36 Zhang, H., Jin, M. \& Xia, Y. Enhancing the catalytic and electrocatalytic properties of Pt-based catalysts by forming bimetallic nanocrystals with Pd. Chem. Soc. Rev. 41, 8035-8049 (2012)

37 Deng, Y.-J., Tian, N., Zhou, Z.-Y., Huang, R., Liu, Z.-L., Xiao, J. \& Sun, S.-G. Alloy tetrahexahedral Pd-Pt catalysts: enhancing significantly the catalytic activity by synergy effect of high-index facets and electronic structure. Chem. Sci. 3, 1157-1161 (2012).

38 Hong, J. W., Kang, S. W., Choi, B.-S., Kim, D., Lee, S. B. \& Han, S. W. Controlled synthesis of Pd-Pt alloy hollow nanostructures with enhanced catalytic activities for oxygen reduction. ACS Nano 6, 2410-2419 (2012)

39 Guo, S., Dong, S. \& Wang, E. Three-dimensional Pt-on-Pd bimetallic nanodendrites supported on graphene nanosheet: facile synthesis and used as an advanced nanoelectrocatalyst for methanol oxidation. ACS Nano 4, 547-555 (2010).

40 Cui, C.-H., Li, H.-H., Yu, J.-W., Gao, M.-R. \& Yu, S.-H. Ternary heterostructured nanoparticle tubes: a dual catalyst and its synergistic enhancement effects for $02 /$ H2O2 reduction. Angew. Chem. Int. Edit. 49, 9149-9152 (2010).

$41 \mathrm{Cui}, \mathrm{C}-\mathrm{H}, \mathrm{Yu}, \mathrm{J}-\mathrm{W} . \mathrm{Li}, \mathrm{H}-\mathrm{H}$, Gao, M-R Liang, H.-W. \& Yu, S.-H Remarkable enhancement of electrocatalytic activity by tuning the interface of $\mathrm{Pd}$-Au bimetallic nanoparticle tubes. ACS Nano 5, 4211-4218 (2011).

42 Chen, Z., Waje, M., Li, W. \& Yan, Y. Supportless Pt and PtPd nanotubes as electrocatalysts for oxygen-reduction reactions. Angew. Chem. Int. Edit. 46, 4060-4063 (2007).

43 Kijima, T., Yoshimura, T., Uota, M., Ikeda, T., Fujikawa, D., Mouri, S. \& Uoyama, S. Noble-metal nanotubes (Pt, Pd, Ag) from lyotropic mixed-surfactant liquid-crystal templates. Angew. Chem. Int. Edit. 43, 228-232 (2003).

$44 \mathrm{Liu}, \mathrm{L}$. \& Pippel, E. Low-platinum-content quaternary PtCuCoNi nanotubes with markedly enhanced oxygen reduction activity. Angew. Chem. Int. Edit. 50, 2729-2733 (2011).

45 Gao, M.-R., Gao, Q., Jiang, J., Cui, C.-H., Yao, W.-T. \& Yu, S.-H. A methanol-tolerant Pt/ CoSe2 nanobelt cathode catalyst for direct methanol fuel cells. Angew. Chem. Int. Edit. 50, 4905-4908 (2011).

46 Fujigaya, T. \& Nakashima, N. Fuel cell electrocatalyst using polybenzimidazolemodified carbon nanotubes as support materials. Adv. Mater. 25, 1666-1681 (2013).

$47 \mathrm{Hu}, \mathrm{C}$., Cheng, $\mathrm{H}$, Zhao, Y., Hu, Y, Liu, Y, Dai, L. \& Qu, L. Newly-designed complex ternary $\mathrm{Pt} / \mathrm{PdCu}$ nano-boxes anchored on three-dimensional graphene framework for highly efficient ethanol oxidation. Adv. Mater. 24, 5493-5498 (2012).

48 Lee, H.-Y., Vogel, W. \& Chu, P. P.-J. Nanostructure and surface composition of Pt and Ru binary catalysts on polyaniline-functionalized carbon nanotubes. Langmuir 27, 14654-14661 (2011)

49 Jeon, S. S., Kim, C., Ko, J. \& Im, S. S. Pt nanoparticles supported on polypyrrole nanospheres as a catalytic counter electrode for dye-sensitized solar cells. J. Phys. Chem. C 115, 22035-22039 (2011).

50 Unni, S. M., Dhavale, V. M., Pillai, V. K. \& Kurungot, S. High Pt utilization electrodes for polymer electrolyte membrane fuel cells by dispersing Pt particles formed by a preprecipitation method on carbon "polished" with polypyrrole. J. Phys. Chem. C 114, 14654-14661 (2010) 
51 Gao, W., Sattayasamitsathit, S., Orozco, J. \& Wang, J. Highly efficient catalytic microengines: template electro-synthesis of polyaniline/platinum microtubes. J. Am. Chem. Soc. 133, 11862-11864 (2011).

$52 \mathrm{He}$, D., Zeng, C., Xu, C., Cheng, N., Li, H., Mu, S. \& Pan, M. Polyaniline-functionalized carbon nanotube supported platinum catalysts. Langmuir 27, 5582-5588 (2011).

53 Shi, L., Liang, R. \& Qiu, J. Controllable deposition of platinum nanoparticles on polyaniline-functionalized carbon nanotubes. J. Mater. Chem. 22, 17196-17203 (2012).

54 Guo, S., Dong, S. \& Wang, E. Polyaniline/Pt hybrid nanofibers: high-efficiency nanoelectrocatalysts for electro-chemical devices. Small 5, 1869-1876 (2009).

55 Chen, S., Wei, Z. D., Qi, X., Dong, L., Guo, Y.-G., Wan, L.-J., Shao, Z. \& Li, L. Nanostructured polyaniline-decorated Pt/C@PANI core-shell catalyst with enhanced durability and activity. J. Am. Chem. Soc. 134, 13252-13255 (2012).

56 Salavagione, H. J., Sanchís, C. \& Morallón, E. Friendly conditions synthesis of platinum nanoparticles supported on a conducting polymer: methanol electrooxidation. J. Phys. Chem. C 111, 12454-12460 (2007).

57 Wang, A.-L., Xu, H., Feng, J.-X., Ding, L.-X., Tong, Y.-X. \& Li, G.-R. Design of Pd/PANI/ $\mathrm{Pd}$ sandwich-structured nanotube array catalysts with special shape effects and synergistic effects for ethanol electrooxidation. J. Am. Chem. Soc. 135, 10703-10709 (2013).
$58 \mathrm{Li}$, X. \& Malardier-Jugroot, C. Confinement eect in the synthesis of polypyrrole within polymeric templates in aqueous environments. Macromolecules 46, 2258-2266 (2013).

59 Sanders, C. R., Hare, B. J., Howard, K. P. \& Prestegard, J. H. Magnetically-oriented phospholipid micelles as a tool for the study of membrane-associated molecules. Prog. Nucl. Magn. Reson. Spectrosc. 26, 421-444 (1994).

60 Vold, R., Prosser, R. \& Deese, A. Isotropic solutions of phospholipid bicelles: a new membrane mimetic for high-resolution NMR studies of polypeptides. J. Biomol. NMR 9, 329-335 (1997).

61 Tian, B. \& Zerbi, G. Lattice dynamics and vibrational spectra of polypyrrole. J. Chem. Phys. 92, 3886-3891 (1990).

62 Sun, Z., Wang, X., Liu, Z., Zhang, H., Yu, P. \& Mao, L. Pt -Ru/CeO2/carbon nanotube nanocomposites: an efficient electrocatalyst for direct methanol fuel cells. Langmuir 26, 12383-12389 (2010).

(c) (i) () $\odot$ This work is licensed under a Creative Commons Attribution-NonCommercial-NoDerivs 3.0 Unported License. To view a copy of this license, visit http://creativecommons. org/licenses/by-nc-nd/3.0/

Supplementary Information accompanies the paper on the NPG Asia Materials website (http://www.nature.com/am) 